\title{
Keterwakilan Perempuan di Parlemen: Komparasi Indonesia dan Korea Selatan
}

\author{
Ella Syafputri \\ University of Western Australia
}

\begin{abstract}
The article examines the similarities and differences in terms of women representation in the parliaments of Indonesia and South Korea. With the methods of literature study, the author constructs the factors inhibiting women's involvement in politics in Indonesia and Korea as a member of the legislature. From 1996 to 2014, Indonesia has more women MPs ratio than Korea. Exceptions only occur in 2004, in which the ratio between women and men in Korea's national parliament surpassed Indonesia. In this article the author argues representation of women in parliament both in Indonesia and South Korea are very influenced by political culture and recruitment system by political party. Both countries apply a minimum quota of women as legislators, as one initiative helps bridging the gender ratio in parliament. However the two Asian countries have not yet succeeded in achieving these targets.
\end{abstract}

Keywords: political representation, parliament, women representatif

\begin{abstract}
Abstrak
Artikel ini mengupas persamaan dan perbedaan dalam hal keterwakilan perempuan di parlemen Indonesia dan Korea Selatan. Dengan metode studi literatur, penulis menyusun faktor-faktor penghambat keterlibatan perempuan Indonesia dan Korea berpolitik sebagai anggota legislatif. Sejak tahun 1996 hingga 2014, Indonesia memiliki lebih banyak perempuan anggota parlemen dibanding Korea. Pengecualian hanya terjadi pada tahun 2004, di mana rasio antara perempuan dan pria di parlemen Korea melampaui Indonesia. Dalam artikel ini penulis berpendapat representasi perempuan di parlemen Indonesia dan Korea Selatan sangat dipengaruhi faktor budaya politik dan sistem rekrutmen oleh partai. Kedua negara menerapkan pendekatan kuota minimum perempuan sebagai anggota legislatif, sebagai salah satu ikhtiar mengurangi jurang rasio gender di parlemen. Namun uniknya dua negara Asia ini belum juga berhasil mencapai target tersebut.
\end{abstract}

Kata kunci: representasi politik, parlemen, representasi wanita 


\section{Pendahuluan}

Selama lebih dari 60 tahun terakhir, Republik Indonesia dan Republik Korea (atau Korea Selatan dan selanjutnya disebut dengan Korea) telah melalui proses transformasi yang mendasar di berbagai aspek kehidupan termasuk politik. Menyatakan kemerdekaan pada tahun 1945, Indonesia langsung memberikan hak politik yang setara antara perempuan dan laki-laki. Perempuan di Indonesia mulai berhak menggunakan hak pilih pada tahun 1945, meskipun pemilu perdana baru digelar pada 1955. Di Korea, perempuan juga mulai memiliki hak aktif memilih pemilu pada tahun 1948-setelah negeri itu merdeka dari penjajahan Jepangdan Perang Korea 1950-1955 (IPU, Women's Suffrage).

Berangkat dari awalan yang hampir bersamaan, Indonesia dan Korea Selatan adalah dua negara yang memiliki banyak kemiripan dalam hal perkembangan keterwakilan perempuan dalam ranah politik nasional. Tercatat dalam sejarah, perempuan Indonesia dan Korea sama-sama pernah menjadi pimpinan tertinggi pemerintahan. Presiden Megawati Setyawati Soekarnoputri adalah perempuan yang menjadi kepala negara di Indonesia selama lebih dari tiga tahun (23 Juli 2001-20 Oktober 2004). Dalam pemilu legislatif demokratis pertama setelah kejatuhan Orde Baru, partai yang dipimpin oleh Megawati Soekarnoputri, Partai Demokrasi Indonesia-Perjuangan (PDI-P), meraih lebih dari 30 persen suara. Namun, perlu digarisbawahi bahwa parlemen pada saat itu memilih Abdurrahman Wahid sebagai presiden dan Megawati Soekarnoputri sebagai wakilnya. Ketika Presiden Abdurrahman Wahid dilengserkan pada tahun 2001, sang wakil presiden pun diambil sumpahnya menjadi presiden. Megawati Soekarnoputriyang merupakan anak sulung dari Presiden Soekarno-tidak pernah menang dalam pemilihan langsung presiden, baik pada tahun 2004 dan 2009 (Republika, 2012).

Sementara, Presiden Park Geun-hye adalah perempuan pertama yang terpilih menjadi Presiden Korea dan dilantik pada 25 Februari 2013 (Telegraph, 2013). Presiden Park naik ke jabatan tertinggi di Korea sekitar
50 tahun setelah ayahnya Park Chung Heeseorang petinggi militer-melakukan kudeta dan menjadi presiden selama 18 tahun hingga akhirnya tewas dibunuh. Selama pemerintahan Presiden Park Chung Hee, Korea berhasil mentransformasikan diri menjadi salah satu negara industri di Asia.

Pencapaian perempuan di sisi eksekutif memang menjadi salah satu barometer kemajuan perempuan dalam hal kualitas berpolitik. Namun, hal ini nampaknya belum maksimal dan tidak seiring sejalan dengan sisi legislatif. Jumlah perempuan sebagai anggota parlemen di Indonesia dan Korea masih tergolong rendah. Dalam artikel ini, penulis akan membahas peringkat keterwakilan perempuan di parlemen Indonesia dan Korea, dikaitkan dengan perkembangan pembangunan kesetaraan gender di kedua negara. Tulisan ini akan membandingkan faktor-faktor yang menghambat perempuan menjadi anggota parlemen. Didukung oleh literatur yang relevan, penulis berpendapat bahwa faktor sosial budaya dan sistem rekrutmen oleh partai politik di kedua negara memainkan peran yang sangat sentral dalam aspek representasi perempuan di badan legislatif. Di dalam kesimpulan, penulis juga akan menawarkan beberapa strategi untuk meningkatkan keterwakilan perempuan di parlemen.

\section{Memaknai Keterwakilan}

Perempuan di Asia, khususnya Indonesia dan Korea, telah menikmati pembangunan yang demikian pesat dalam setengah abad terakhir. Pembangunan ekonomi, modernisasi, dan demokratisasi yang sangat dramatis telah mengubah wajah kedua negara dari puingpuing sisa perang menjadi negerinya gedung pencakar langit. Saat ini, Korea adalah ekonomi terbesar ke-4 di Asia dengan pendapatan per kapita, pada tahun 2013 diperkirakan mencapai 33.200 dolar Amerika (CIA, 2014). Korea juga masuk ke dalam kategori negara dengan tingkat pembangunan manusia tertinggi dengan peringkat 12 di United Nations Human Development Index (HDI) tahun 2012 (UNDP, 2013). Sementara itu, Indonesia masih terseok di urutan 121 rangking HDI dengan berbagai masalah di 
sektor pendidikan dan layanan kesehatan. Pendapatan per kapita Indonesia juga tergolong rendah, yakni sekitar 5.200 dolar Amerika di tahun 2013 (CIA, 2014).

Rasio populasi antara perempuan dan laki-laki di Indonesia dan Korea adalah 1:1 (CIA, 2014). Dengan nalar yang sederhana, perempuan sepatutnya mendapat ruang kesempatan yang sama untuk terlibat dalam politik dan menjadi wakil bagi kaumnya. Berbagai literatur pun menyebutkan bahwa jumlah perempuan di parlemen sangat erat hubungannya dengan kemajuan di sektor kebijakan publik terkait dengan kepentingan perempuan dan anak (Carroll, 2001; Swers, 2001). Namun pada kenyataannya, jumlah perempuan yang terlibat secara aktif di dunia politik, dan lebih spesifik lagi menjadi anggota parlemen, masih sangat terbatas (Iwanaga, 2008).

Dikutip dari laporan IPU 2014, rasio perempuan terhadap laki-laki yang menjadi anggota parlemen Indonesia dan Korea masih di bawah rata-rata dunia 21,7 persen-di mana 35.728 anggota parlemen adalah laki-laki sementara perempuan hanya 9.891 orang.
Indonesia berada di ranking 82 , dengan rasio representasi perempuan 18,6 persen sedangkan Korea ada di urutan 91 dengan 15,7 persen (IPU, 2014). Barometer lain untuk melihat kesetaraan gender di politik adalah laporan The Global Gender Gap (World Economic Forum, 2013) dan Gender Inequality Index (GII) yang diterbitkan oleh UNDP. Seperti terlihat di tabel komparasi di bawah ini, Indonesia dan Korea memiliki tingkat keterwakilan perempuan di parlemen yang relatif tidak jauh berbeda, namun tingkat pembangunan manusia (HDI) Korea jauh melampaui Indonesia. Indonesia masuk ke peringkat yang terbelakang dari Korea dalam dua rangking versi UNDP: HDI dan GII (UNDP, 2013), namun unggul menurut Gender Gap versi World Economic Forum. Perbedaan rangking ini disebabkan oleh cara pengukuran dan pilihan indikator yang berbeda antara GII dan Gender Gap. World Economic Forum memperhitungkan jumlah tahun perempuan menjadi pemimpin dalam 50 tahun terakhir dan prosentase perempuan yang menjabat sebagai menteri (sisi eksekutif), selain rasio perempuan di dewan (legislatif).

\begin{tabular}{|l|c|c|}
\hline \multicolumn{1}{|c|}{ Indikator } & Indonesia & Korea \\
\hline IPU 2014 & 82 & 91 \\
\hline HDI 2012 & 121 & 12 \\
\hline GII 2012 & 106 & 27 \\
\hline Gender Gap 2013 & 95 & 111 \\
\hline \multicolumn{2}{|c|}{ Tabel 1. Perbandingan tingkat kesetaraan perempuan antara }
\end{tabular}

Tabel 1. Perbandingan tingkat kesetaraan perempuan antara

Indonesia dan Korea Selatan dari berbagai rangking skala indikator.

Terlepas dari perbedaan peringkat Indonesia dan Korea di beberapa skala indikator, konsep keterwakilan sendiri memerlukan analisa yang lebih mendalam guna melihat apakah suara perempuan memang tidak didengar bila jumlah perempuan yang menjadi anggota dewan sangat kecil. Representasi memiliki empat bentuk yaitu: formal, deskriptif, substantif atau responsif, dan simbolik (Pitkin, 1967). Keterwakilan formal memiliki fokus di tataran aturan hukum tentang prosedur bagaimana wakil dipilih atau diganti. Sementara itu keterwakilan deskriptif diartikan dengan keterwakilan yang secara komposisi proporsional antara yang mewakili dan diwakili. Tingkat keterwakilan ini bisa dirinci lagi menjadi keterwakilan di sisi fungsional (kesamaan pekerjaan atau fungsi sosial di masyarakat) dan sisi sosial yang meliputi aspek suku, gender, etnis, dan kelas sosial (Norris \& Franklin, 1997). Jenis keterwakilan deskriptif adalah yang paling kerap dijadikan acuan melihat komposisi di lembaga legislatif karena bisa dengan mudah terlihat latar belakang para anggota dewan berdasarkan gender, etnis, dan status sosial mereka.

Tipe representasi berikutnya adalah substantif atau responsif, di mana orang yang menjadi wakil harus bertindak dan 
memperjuangkan kepentingan orang-orang yang mereka wakili. Wujud dari keterwakilan ini harus tercermin di kebijakan atau hukum yang sejalan dengan kepentingan pemberi mandat. Jenis yang terakhir adalah representasi simbolis, yang kata kuncinya terletak di simbol atau simbolisasi. Contoh dari representasi ini adalah bendera sebagai wakil atau simbol dari sebuah bangsa. Kekuatan representasi ini bukan di sisi siapa atau apa yang menjadi simbol, tapi seberapa kuat simbol tersebut dipandang oleh orang yang melihatnya (Pitkin, 1967).

Dalam bukunya yang berjudul "The Politics of Presence”, Anne Phillips (1995) menjabarkan teori politik kehadiran yang menyebutkan bahwa politisi perempuan memiliki kelengkapan terbaik untuk mewakili kepentingan kaumnya. Teori ini memprediksi bahwa ada kaitan yang sangat erat antara representasi deskriptif dan representasi substantif. Dengan kata lain, bila keterwakilan secara deskriptif (jumlah perempuan di parlemen) meningkat, maka kepentingan perempuan pun akan semakin digaungkan di parlemen. Pendapat Phillips ini didasari oleh perbedaan laki-laki dan perempuan dalam kehidupan sehari-hari. Perbedaan ini meliputi pola pengasuhan anak, pendidikan dan pekerjaan, jenis pekerjaan di dunia kerja, paparan kekerasan terhadap perempuan, dan kejahatan seksual yang dialami oleh perempuan. Namun pada akhirnya, Phillips tetap tidak bisa memastikan apakah jumlah yang lebih banyak di parlemen akan mengubah agenda politik untuk lebih mengarusutamakan kepentingan perempuan, ia menggunakan istilah "shot in the dark" (Phillips, 1995, p. 83).

Keraguan ini juga dipaparkan oleh Heiki Hermanns yang mendapati tingkat representasi perempuan yang rendah di Korea ternyata tidak membuat kebijakan untuk memperhatikan kepentingan perempuan menjadi berkurang. Keberhasilan Korea mengagendakan program pro-perempuan terlihat hasilnya di angka kematian ibu dan bayi yang rendah, pencapaian tingkat pendidikan antara laki-laki dan perempuan yang setara, rendahnya angka pertumbuhan penduduk, dan akses kesehatan yang sama antara laki-laki dan perempuan:

\begin{abstract}
"Despite low levels of female legislative representation, however, South Korea has introduced progressive women's policies that are more advanced than in other countries with higher levels of female representation." (Hermanns, 2006, p.4)
\end{abstract}

Berangkat dari fakta ini, Hermanns berpendapat bahwa ada cara lain untuk mengarusutamakan kepentingan perempuan dan anak, selain representasi langsung perempuan sebagai anggota legislatif. Alternatif ini juga bisa menjadi pertimbangan bagi strategi memperbaiki pembangunan perempuan di Indonesia yang belum sepenuhnya bergaris lurus dengan perkembangan representasi perempuan di parlemen. Indeks pembangunan manusia di Indonesia masih jauh tertinggal padahal jumlah perempuan yang menjadi anggota dewan terus mendekati ke titik seimbang dengan laki-laki.

\section{Persamaan dan Perbedaan}

Rasio keterwakilan perempuan di parlemen nasional; Kuk Hoe di Korea dan MPR (Majelis Permusyawaratan Rakyat) di Indonesia menunjukkan tren yang relatif serupa. Dari tahun ke tahun, rasio ini terus meningkat meskipun masih berada di bawah rata-rata dunia. Korea bahkan masih di bawah rata-rata kawasan Asia (IPU, 2014). Dari sisi kesamaan, kedua negara adalah penandatangan Konvensi Penghapusan Segala Bentuk Diskriminasi terhadap Perempuan/CEDAW (www.cedawseasia.org). Konvensi ini diadopsi oleh Perserikatan Bangsa-Bangsa (PBB) pada tahun 1979 dan mulai berlaku pada 3 Desember 1981. Per 18 Maret 2005, terdapat 180 negara atau lebih dari 90 persen anggota $\mathrm{PBB}$ yang menjadi Negara Peserta Konvensi. CEDAW menetapkan secara universal berbagai prinsip persamaan hak antara perempuan dan lakilaki di berbagai bidang seperti politik, ekonomi, sosial, budaya dan sipil. Konvensi ini mendorong agar negara penandatangan memberlakukan perundang-undangan nasional yang melarang diskriminasi dan mengadopsi tindakan afirmatif guna mempercepat kesetaraan de facto antara laki- 
laki dan perempuan-termasuk di antaranya mengubah tradisi atau kebiasaan yang berdasarkan kepada pandangan superioritas atau stereotip salah satu jenis kelamin.

Indonesia dan Korea juga sama-sama menandatangani Beijing Declaration and Platform for Action (BPFA) 1995, sebuah rencana strategi bersama bangsa-bangsa dalam upaya memperbaiki keadaan di 12 masalah menyangkut perempuan dan anak. Dua belas masalah itu adalah: perempuan dan kemiskinan, pendidikan dan pelatihan bagi perempuan, perempuan dan kesehatan, kekerasan terhadap perempuan, perempuan dan konflik bersenjata, perempuan dan ekonomi, perempuan dalam kedudukan pemegang kekuasaan dan pengambil keputusan, mekanisme institusional untuk kemajuan perempuan, hak-hak asasi perempuan, perempuan dan media, perempuan dan lingkungan hidup, dan yang terakhir adalah anak-anak perempuan.

Bergabungnya Indonesia dan Korea di berbagai konvensi, kovenan, atau komitmen internasional tentang kesetaraan gender adalah kesamaan yang patut dijadikan catatan. Penandatanganan CEDAW dan BPFA menjadi landasan pemerintah nasional memperbaiki tingkat kesetaraan gender, karena pemerintah menyusun pelbagai kebijakan, reformasi, serta perundang-undangan yang mengimplementasikan semangat dua konvensi internasional tadi.

\begin{tabular}{|l|l|l|}
\hline \multicolumn{1}{|c|}{ Aspek Pembanding } & \multicolumn{1}{c|}{ Indonesia } & \multicolumn{1}{c|}{ Korea } \\
\hline Konvensi internasional & CEDAW dan BPFA & CEDAW dan BPFA \\
\hline Pemilu dilakukan & 5 tahun sekali & 4 tahun sekali \\
\hline Kursi parlemen & 560 : pemilihan langsung & $\begin{array}{l}\text { 300: 246 pemilihan langsung } \\
54 \text { pemilihan proporsional }\end{array}$ \\
\hline Sistem kuota & $30 \%$ & $\begin{array}{l}30 \% \text { untuk pemilihan langsung } \\
50 \% \text { untuk pemilihan } \\
\text { proporsional }\end{array}$ \\
\hline Mulai sistem kuota & Pemilu tahun 2004 & Pemilu tahun 2000 \\
\hline Uang deposit & Tidak ada & Ada (15 juta won) \\
\hline Usia minimal memilih & 17 tahun & 19 tahun \\
\hline Usia dipilih & 21 tahun & 25 tahun \\
\hline
\end{tabular}

Tabel 2. Persamaan dan perbedaan sistem pemilihan anggota legislatif di Indonesia dan

Korea

(Sumber: Inter-Parliamentary Union 2014)

Selain aspek persamaan, sistem pemilihan anggota dewan di Indonesia dan Korea memiliki beberapa perbedaan. Seperti terlihat di Tabel 2, kursi parlemen yang diperebutkan para kandidat ada yang dengan pemilihan langsung, ada pula yang sistem proporsional. Di Indonesia, batas usia boleh memilih adalah 17, sementara di Korea 19 tahun. Usia minimum untuk bisa menjadi calon legislatif di Indonesia adalah 21 tahun, sedangkan di Korea 25 tahun (IPU, 2013). Di sistem pemilihan Korea dikenal dengan deposit uang sebanyak 15 juta won atau setara dengan Rp165 juta (1 won Korea = Rp11) (IPU, 2014). Uang ini akan dikembalikan sepenuhnya kepada caleg bila ia berhasil meraih suara minimal 15 persen dari surat suara sah. Deposit ini akan dikembalikan separuh bila kandidat hanya berhasil meraih suara di atas 10 persen tapi tidak sampai 15 persen. Uang juga baru bisa dipulangkan bila partai politik tempat caleg berafilitasi berhasil meraih minimal satu kursi di parlemen.

Di Indonesia, tindakan afirmatif Pemerintah Indonesia untuk mengatasi masalah kekurangan representasi gender dalam politik tercermin dari Undang-undang tentang Pemilihan Umum tahun 2008. Reformasi pertama adalah sistem daftar terbuka, di mana pemilih boleh memilih partai dan calon legislatif (caleg). Caleg yang mendapatkan suara terbanyak berhak meraih kursi meskipun nomor urutnya bukan yang teratas (Parawansa, 2005). Reformasi sistem pemilihan umum juga membuka peluang bagi perempuan untuk terlibat lebih banyak di 
parlemen dengan aturan yang menyebutkan bahwa partai politik wajib menempatkan minimal 30 persen perempuan di dalam daftar calon legislatif (UNDP, 2010).

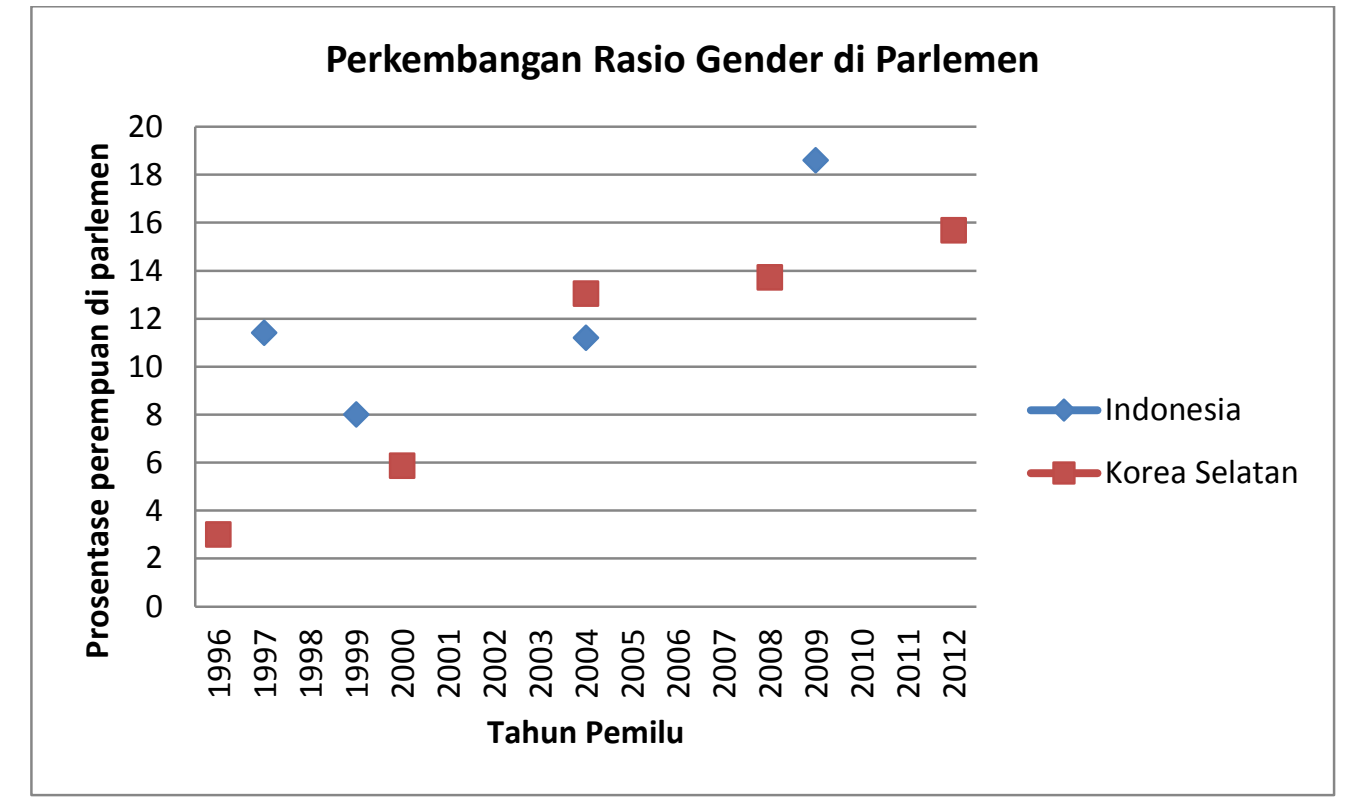

Tabel 2. Perkembangan Rasio Gender di Parlemen Indonesia dan Korea periode 1996-2012

(Sumber: IPU 2014)

Konsep kuota memang telah menjadi salah satu strategi negara-negara di dunia dalam upaya mereka melibatkan lebih banyak perempuan ke dalam politik parlemen (Krook, 2009). Jurus ini juga diterapkan di Korea. Mulai tahun 2000, partai politik di Korea Selatan diwajibkan menempatkan 30 persen kandidat perempuan di dalam daftar caleg (Hermanns, 2006). Kebijakan kuota membawa peningkatan yang moderat dalam hal jumlah perempuan anggota dewan, dari 9 di periode 1996-2000 menjadi 16 orang di periode 2000-2004 (kenaikan dari 3 persen ke 5,86 persen kursi parlemen). Bahkan di tahun 2002, skema kuota ditingkatkan lagi menjadi 50 persen untuk pemilu lokal dengan sistem proporsional, sementara kuota 30 persen diterapkan untuk sistem pemilihan langsung. Dampak dari kebijakan ini langsung terasa dengan peningkatan tajam rasio perempuan di parlemen menjadi 13,04 persen untuk periode 2004-2008 seperti bisa dilihat di Tabel 2.

\section{Faktor-faktor Penghambat}

Minimnya keterlibatan perempuan dalam politik dan parlemen bisa dirujuk dari pelbagai aspek. Literatur menyebutkan tiga alasan rendahnya angka partisipasi perempuan: hambatan struktural, institusi politik, dan budaya politik (Lovenduski, Campbell, \& Sampson-Jacent, 2002). Kendala struktural memiliki peran yang sangat sentral dalam komposisi gender di politik (Reynolds, 1999), sebab pembangunan sosio-ekonomi berjalan seiring dengan keterwakilan perempuan di parlemen, sebagaimana tercermin dalam laporan PBB terkait dengan progres kesetaraan gender di sektor ekonomi, pendidikan, harapan hidup, dan kesehatan (Norris \& Inglehart, 2001).

Dalam komparasi Indonesia dan Korea ini, penulis memusatkan pembahasan di dua faktor penghambat berikutnya yaitu benturan budaya patriaki yang sangat kental dan sistem rekrutmen calon legislatif oleh partai politik. Dua faktor ini menjadi sorotan di berbagai literatur tentang politik parlemen Indonesia dan Korea. Pada Konstitusi Korea Pasal 11 tegas disebutkan bahwa "semua warga negara setara di hadapan hukum dan tidak boleh ada diskriminasi dalam politik, ekonomi, sipil atau kehidupan budaya berdasarkan jenis kelamin, agama atau status sosial”. Di Pasar 24 kembali ditegaskan bahwa perempuan memiliki hak yang sama dengan laki-laki untuk bebas memilih dalam pemilu. Namun, di negeri dengan pandangan hidup yang sangat dipengaruhi oleh Konfusianisme ini, korelasi 
gender di Korea sangat didominasi laki-laki (Kim, 1994). Konfusianisme adalah filsafat dan satuan standar sosial dan etika yang diadopsi oleh Dinasti Yi (1392-1910)-monarki terakhir di Korea-sebagai landasan program sosiopolitik. Prinsip dasar dari filsafat ini adalah pentingnya harmoni antara alam dan hubungan manusia. Ajaran Konfusius membuat dikotomi peran publik dan domestik antara laki-laki dan perempuan (Lee, 1996). Perempuan di Korea idealnya "menjadi ibu rumah tangga dan mengurus anak, sementara laki-laki menjadi wakil keluarga di dunia luar" (Hermanns, 2006, p. 2).

Hal serupa juga dialami perempuan Indonesia (Davies \& Idrus, 2010). Pandangan budaya di Indonesia melihat seorang perempuan adalah sukses bila keluarganya juga terurus dan berhasil. Di sisi lain, politisi perempuan dinilai terlibat dalam politik sebagai aktivitas sampingan karena keluarganya sudah dipenuhi kebutuhannya. Aspek lain yang membuat perempuan Indonesia kurang meminati dunia politik adalah stereotip tentang politik yang dikaitkan dengan citra-citra negatif seperti politik adalah kotor, korup, dan licik. Sisi lain yang menarik untuk dijadikan perbandingan adalah faktor agama. Reynolds (1999) mendapati negaranegara dengan mayoritas penganut agama Kristen (Katolik atau Protestan) memiliki keterwakilan perempuan yang lebih tinggi di parlemen dan kabinet jika dibandingkan dengan negara-negara dengan mayoritas penganut agama Islam, Buddha, Hindu, Judisme, dan Konfusiusme.

Selain benturan budaya, perempuan di Indonesia dan Korea juga masih harus menghadapi tantangan dari sistem rekruitmen oleh partai politik untuk bisa dicalonkan sebagai caleg (Blackburn, 1999; Kim \& Chun, 1996). Di Korea, ajaran Konfusius masih mendominasi alam berpikir politik sehingga negeri itu pun mendapat julukan "patriarchal democracy" (Soh, 1993). Perempuan kurang diminati oleh partai politik karena pandangan tradisional yang kurang mendukung perempuan menjadi politisi dan keraguan terhadap kapasitas perempuan dalam urusan politik (Moon, 2003). Sementara di Indonesia, pandangan patriarki juga mendominasi kebudayaan di pulau-pulau besar. Kondisi ini sebenarnya dilembagakan oleh Orde Baru yang mengekang peran politik perempuan sebatas peran domestik: istri dan ibu (Blackburn, 1999). Padahal, perempuan di Indonesia pada era perjuangan kemerdekaan justru memerankan fungsi politik sebagai pucuk pimpinan sebagai ratu dan panglima perang di Aceh, serta mitra diskusi politik formal di Makassar (Davies \& Idrus, 2010).

Untuk memahami pengaruh partai politik dalam representasi perempuan di parlemen, patut diketahui bahwa sistem pemilu legislatif di Korea terdiri atas dua kelompok: mereka ada yang dipilih (elected) berdasarkan jumlah suara paling banyak di daerah tertentu (pemilihan langsung) dan ada yang ditunjuk (appointed) berdasarkan daftar calon legislatif nasional yang disusun oleh partai politik (pemilihan proporsional). Soh (1993) menjelaskan mereka yang dipilih harus menunjukkan aspek kekuatannya sebagai individu (personhood) yang memang pantas mendapatkan suara, sementara perempuan yang ditunjuk biasanya direkruit oleh partai karena aspek "womenhood" dan dipandang bisa mewakili kepentingan perempuan dan anak di arena politik. Di Indonesia, pemilihan anggota DPR dan DPD (Dewan Perwakilan Daerah) juga memberikan dampak yang berbeda bagi perempuan. Untuk menjadi anggota DPR, perempuan harus terdaftar di salah satu daftar caleg partai politik, sementara untuk menjadi anggota DPD perempuan tampil sebagai individu dan merebut suara konstituen yang lebih luas. Yang menarik untuk dicatat adalah tidak ada ketentuan kuota 30 persen perempuan di DPD, tapi jumlah representasi perempuan justru lebih tinggi di DPD ketimbang di DPR (UNDP, 2010). Pada periode 2004-2009, rasio perempuan sebagai anggota DPD adalah 22,58 persen sementara DPR adalah 11,8 persen. Pada periode berikutnya 2009-2014, rasio perempuan di DPD adalah 26,52 persen sedangkan di DPR 18,04 persen.

Di Indonesia, partai politik lebih suka memilih perempuan yang populer ketimbang perempuan yang memang benar-benar aktif di politik (Parawansa, 2014). Pekerja seni atau pesohor yang kerap muncul di televisi akan 
dijadikan caleg oleh partai politik meskipun pengetahuan dan pengalaman berorganisasi di dunia politik sangat minim. Sistem kuota juga membuat partai terkesan mengambil jalan instan, asal pilih dan asal memenuhi kuorum jumlah caleg perempuan agar tidak dianggap melanggar Undang-undang Pemilu. Dalam wawancaranya dengan penulis, Parawansa menjelaskan perempuan yang bertahun-tahun menjadi pengurus partai berpeluang mendapat "nomor sepatu" sementara perempuan yang baru bergabung ke partai, tapi populer di masyarakat, bisa langsung mendapat nomornomor atas. Ini karena penentuan nomor urut dilakukan oleh elit partai dan mayoritas mereka adalah laki-laki. Kondisi ini memicu fenomena perempuan-perempuan minim pengetahuan dan keterampilan politik, tapi duduk di parlemen karena mereka adalah "istrinya siapa atau putrinya siapa" (Hulwani, 2014).

Biaya politik yang demikian tinggi juga membuat perempuan Indonesia dan Korea kesulitan menampilkan diri untuk berkompetisi mendapatkan kursi parlemen. Anggota DPR dari Fraksi Golkar, Bambang Soesatyo, mengaku harus merogoh kocek hingga Rp1 miliar untuk kampanye di pemilu 2009 (Soesatyo, 2013). Pengeluarannya meliputi biaya transportasi, penginapan, logistik alat bantu kampanye, iklan di media lokal, biaya bantuan sosial, biaya pengumpulan massa, dan makanan untuk tempat sosialisasi. Menariknya, biaya terbesar adalah untuk membayar saksi di tiap-tiap TPS yang masing-masing Rp50.000-Rp100.00o. Sebagai gambaran, di daerah pemilihan Bambang ada 8.00o TPS. Dalam pengakuannya, Bambang menyebut Golkar tidak menyediakan subsidi untuk kampanye calegnya. Caleg dari Partai Gerindra Aryo Djojohadikusumo bahkan menegaskan tidak ada demokrasi yang murah dan ia mengaku mengeluarkan dana Rp6 miliar agar terpilih menjadi anggota DPR (Djojohadikusumo, 2014). Pengeluaran terbesar untuk meraih 210.00o suara konstituen adalah pembuatan kaos, topi, media sosialisasi, serta tim berisi 150 orang yang digaji per bulan. Setiap hari Aryo harus mengeluarkan dana Rp 5 juta untuk mengoperasikan 8 mobil ambulans yang memberikan layanan kesehatan gratis sekaligus media berkampanye.

Sementara itu Partai politik di Korea terkenal dengan pendekatannya yang "partycentered" karena semua dana masuk untuk kampanye-baik dari sumbangan, iuran anggota, atau subsidi dari pemerintah-harus melalui partai dan baru dikeluarkan sesuai dengan kebijakan partai (Shin, Jin, Gross, \& Eom, 2005). Tipe sistem politik "partycentered" ini ditandai oleh struktur kekuasaan partai yang sangat kuat dan mengandalkan figur pemimpin. Ciri berikutnya adalah kandidat akan menang di daerah yang memang partai si kandidat kuat di sana. Sebagai contoh, bila pemimpin partai A adalah orang kelahiran Kota $\mathrm{X}$, maka kandidat legislatif dari partai A akan punya peluang yang sangat tinggi untuk menang di Kota X.

\section{Kesimpulan}

Keterwakilan perempuan di parlemen Indonesia dan Korea dihambat oleh faktorfaktor yang relatif sama. Dari pembahasan di atas, penulis memusatkan perhatian kepada dua unsur utama: pandangan patriaki yang sangat mengakar di budaya Asia dan sistem rekrutmen calon anggota parlemen yang dilakukan oleh partai politik. Perempuan di Indonesia dan Korea sama-sama dihambat oleh budaya yang patriarkis dan sistem rekrutmen partai politik yang ruhnya adalah memprioritaskan laki-laki ketimbang perempuan untuk urusan berpolitik. Di sisi lain, sistem pemilihan di Indonesia dan Korea berbeda dalam hal biaya kampanye. Di Indonesia, perempuan dan laki-laki yang ingin menjadi anggota dewan harus menanggung sebagian besar biaya berkampanye. Di Korea, biaya kampanye dikeluarkan oleh partai dan diatur dengan pengawasan internal serta eksternal yang ketat. Hambatan di biaya kampanye ini cukup penting untuk menjadi bahan pembanding peta politik parlemen dua negara.

Beberapa strategi yang dapat digunakan untuk mengatasi masalah ini adalah membangun kesadaran berbasis konteks yang spesifik tentang keterwakilan perempuan di lembaga legislatif, peningkatan pendidikan bagi perempuan dan sistem 
ekonomi yang stabil akan memfasilitasi perempuan masuk ke ranah politik (Gollifer, 2013). Untuk mengatasi benturan budaya, mungkin tidak bisa diselesaikan dalam waktu singkat dengan kampanye kesadaran publik, namun pada masa mendatang perubahan nilai yang dibawa oleh proses modernisasi akan membuka ruang implementasi strategi aksi afirmatif (Norris \& Inglehar, 2000). Agar lebih sukses dalam pemilu, perempuan harus menggalang kerjasama dengan konstituen secara tulus dan berkesinambungan. Kehadiran mereka sepatutnya bukan hanya pada musim pemilu, sehingga menimbulkan kesan "politisi karbitan", melainkan secara terus menerus memberikan pendidikan politik dan menyerap aspirasi dari kaumnya di lapangan. Terlepas dari kondisi rasio gender di parlemen Indonesia dan Korea sekarang, sistem kuota memang akan meningkatkan jumlah perempuan berparlemen (Dahlerup, 1998), namun pertanyaan yang lebih kunci adalah bagaimana memastikan perempuan di parlemen bisa lebih memperjuangkan kepentingan kaumnya lewat kebijakan (Tinker, 2004). Karena kebijakan pro-perempuan dan anak bukan hanya ditentukan di parlemen, tapi juga harus melibatkan semua pemangku kepentingan, berbagai unsur masyarakat, dan tentu saja rakyat sebagai pemberi mandat.

\section{Daftar Pustaka}

\section{Buku}

Carroll, S. (2001) Representing Women: Women State Legislators as Agents of Policy-Related Change. In S. Carroll, The Impact of Women in Public Office (pp. 3-21). Bloomington: Indiana University Press.

Gollifer, S. (2013) Beyond almost all politicians there are women in the shadow: Cambodian women's experiences of local governance. In Journeys from Exclusion to Inclusion: Marginalized women's success in overcoming political exclusion (pp. 294-325). Stockholm: IDEA.

Iwanaga, K. (2008) Women's political participation and representation in
Asia: obstacles and challenges. Copenhagen: NIAS Press.

Krook, M. L. (2009) Quotas for women in politics: Gender and candidate selection reform worldwide. Oxford: Oxford University Press.

Lovenduski, J., Campbell, R., \& SampsonJacent, J. (2002) Women, Public Life and Democracy. London: Pluto Press.

Moon, S. (2003) Redrafting Democratization Through Women's Representation and Participation in the Republic of Korea. In Korea's Democratization (pp. 107154). Cambridge: Cambridge University Press.

Parawansa, K. I. (2005) Enhancing Women's Political Participation in Indonesia. In J. Ballington, \& A. Karam, Women in Parliament: Beyond Numbers (pp. 8290). Stockholm: IDEA.

Phillips, A. (1995) The Politics of Presence. Oxford: Oxford University Press.

Pitkin, H. (1967) The Concept of Representation. Berkeley: University of California Press.

\section{Jurnal}

Blackburn, S. (1999) Women and Citizenship in Indonesia. Australian Journal of Political Science , 189-204.

Davies, S. G., \& Idrus, N. I. (2010) Participating in Parliamentary Politics: Experiences of Indonesian Women 1995-2010. Journal of Indonesian Social Sciences and Humanities , 81-97.

Hermanns, H. (2006) Women in South Korean politics: a long road to equality. Journal of Multidisciplinary International Studies .

Kim, R. (1994) The Legacy of Institutionalized Gender Inequality in South Korea: The Family Law. Boston College Third World Law Journal .

Kim, Y., \& Chun, K. (1996) A Study of the Political and Social Consciousness of Korean Women. Women's Studies Forum, vol. 2 , 117-147.

Norris, P., \& Franklin, M. (1997) Social Representation Norris, Pippa, and Mark 
Franklin. European Journal of Political

Research $32,185-210$.

Norris, P., \& Inglehar, R. (2000) Cultural Barriers to Women's Leadership: A Worldwide Comparison. International Political Science Association World Congress, (pp. 1-30). Quebec City. . (2001) Cultural Obstacles to Equal Representation. Journal of Democracy , 126-140.

Reynolds, A. (1999) Women in the Legislatures and Executives of the World: Knocking at the Highest Glass Ceiling. World Politics 51(4).

Shin, M., Jin, Y., Gross, D. A., \& Eom, K. (2005) Money matters in party-centered politics: campaign spending in Korean congressional elections. Electoral Studies , 85-101.

Soh, C.-H. S. (1993) Sexual equality, male superiority, and Korean women in politics: changing gender relations in a "Patriarchal Democracy". Sex Roles , 7390.

Swers, M. (2001) Research on Women in Legislatures: What Have We Learned, Where are We Going? Women and Politics , 167-185.

Tinker, I. (2004) Quotas for women in elected legislatures: Do they really empower women? Women's Studies International Forum 27, 531-546.

\section{Tesis}

Lee, M. (1996) Women's Education, Work, and Marriage in Korea: Women's Lives Under Institutional Conflict. PhD thesis . University of California.

\section{Wawancara}

Hulwani, N. (2014, April 1) (E. Syafputri, Interviewer)

Parawansa, K. I. (2014, April 2) (E. Syafputri, Interviewer)

\section{Artikel Online}

CIA. (2014, April 14) The World Factbook [Online], available from The World Factbook:

$<$ https://www.cia.gov/library/publicati ons/the-world-factbook/geos/ks.html> [Accessed on 19 April 2014].

Dahlerup, D. (1998). Using quotas to increase women's political representation [Online], available from: <http://www.intidea.se/women/> [Accessed on 4 April 2014].

Djojohadikusumo, A. (2014, January 26). Caleg Gerindra: Biaya Kampanye Minimal Rp6 Miliar [Online], available from: Kompas.com: <http://nasional.kompas.com/read/20 14/01/26/1748157/Caleg.Gerindra.Biay a.Kampanye.Minimal.Rp.6.Miliar> [Accessed on 19 April 2014].

IPU. (2013, March 5). IPU PARLINE database: Indonesia [Online], available from: www.ipu.org: <http://www.ipu.org/parlinee/reports/2147.htm $>$ [Accessed on 5 April 2014].

. (2014, March 5). IPU PARLINE database: Republic of Korea [Online], available from: www.ipu.org: http://www.ipu.org/parlinee/reports/2259.htm > [Accessed on 5 April 2014].

. (2014, February 1). Women in National Parliaments [Online], available from: Inter-Parliamentary Union: <http://www.ipu.org/wmne/classif.htm> [Accessed on 19 April 2014].

. (n.d.). Women's Suffrage [Online], available from: www.ipu.org: $<$ http://www.ipu.org/wmne/suffrage.htm $>$ [Accessed on 12 April 2014].

Republika. (2012, August 13) [Online], available from: Republika: $<$ http://www.republika.co.id/berita/na sional/politik/12/08/13/m8op7dsurvei-jsi-megawati-capres-terpopuler $>$ [Accessed on 19 April 2014].

Soesatyo, B. (2013, April 23) [Online]. vivanews.com. Available from: vivanews.com: <us.politik.news.viva.co.id/news/read/ 407387-biaya-caleg-minimal-Rp1miliar-dipakai-apa-saja> [Accessed on 12 April 2014]. 
Telegraph. (2013, February 25) [Online], available from: Telegraph: <http://www.telegraph.co.uk/news/wo rldnews/asia/southkorea/9891902/Par k-Geun-Hye-becomes-South-Koreasfirst-female-president.html> [Accessed on 19 April 2014].

UNDP. (2013). Human Development Report 2013 - The Rise of the South: Human Progress in a Diverse World. [Online], available from: UNDP.org: <http://hdr.undp.org/en/2013-report> [Accessed on 19 April 2014].

. (2010, May). Partisipasi Perempuan dalam Politik dan Pemerintah: Makalah Kebijakan [Online], available from: $\quad$ www.undp.or.id: <http://www.undp.or.id/pubs/docs/W omen\%27s\%2oParticipation\%20in\%20 Politics\%20and\%2oGovernment\%20\%20Bahasa.pdf> [Accessed on 19 April 2014].

. (2013, March 23). UN Data [Online], available from: www.data.un.org: $<$ http://data.un.org/DocumentData.as px?q=Gender+Development+index\&id $=332>$ [Accessed on 19 April 2014].

World Economic Forum [Online]. (2013, October 24), available from: Global Gender Gap: $<$ http://www.weforum.org/issues/glob al-gender-gap $>$ [Accessed on 19 April 2014].

www.cedaw-seasia.org [Online]. (n.d.)., available from: <http://cedawseasia.org/docs/indonesia/CEDAW_te xt_Bahasa.pdf> [Accessed on 19 April 2014]. 
